\title{
A novel psoralen derivative-MPFC enhances melanogenesis via activation of p38 MAPK and PKA signaling pathways in B16 cells
}

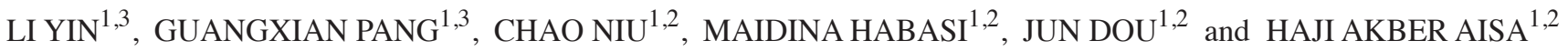 \\ ${ }^{1}$ The Key Laboratory of Plant Resources and Chemistry of Arid Zone, Xinjiang Technical Institute of Physics and Chemistry, \\ Chinese Academy of Sciences; ${ }^{2}$ State Key Laboratory Basis of Xinjiang Indigenous Medicinal Plants Resource Utilization, \\ Urumqi, Xinjiang 830011; ${ }^{3}$ University of The Chinese Academy of Sciences, Beijing 100039, P.R. China
}

Received November 10, 2016; Accepted February 9, 2018

DOI: $10.3892 / \mathrm{ijmm} .2018 .3529$

\begin{abstract}
As an active compound, psoralen is present in various Chinese herbal medicines and has exhibited significant activity in skin disease treatment. Its derivative 8-methoxypsoralan (8-MOP) is the most commonly used drug to induce repigmentation of vitiligo. In our previous screening assays, 4-methyl-6-phenyl-2H-furo[3,2-g]chromen-2-one (MPFC), a psoralen derivative, was identified as more effective tyrosinase and melanin activator than the positive control 8-MOP in consideration of low doses, as well as low toxicity. The overall purpose of this study was to characterize the melanogenic effect and mechanisms of MPFC in B16 cells. The melanin biosynthesis effects of MPFC were determined by examination of cellular melanin contents, tyrosinase activity assay, cyclic adenosinemonophosphate (cAMP) assay, and western blotting of MPFC-stimulated B16 mouse melanoma cells. Our results showed that MPFC enhanced both melanin synthesis and tyrosinase activity in a concentration-dependent manner as well as significantly activated the expression of melanogenic proteins such as tyrosinase, tyrosinase-related protein-1 and tyrosinase-related protein-2. Western blot analysis showed that MPFC increased the phosphorylation of p38 mitogen-activated protein kinase and cAMP response element-binding protein (CREB) as well as the expression of microphthalmia-associated transcription factor (MITF). Moreover, MPFC stimulated intracellular cAMP levels and induced tyrosinase activity and melanin synthesis were attenuated by $\mathrm{H} 89$, a protein kinase $\mathrm{A}$ inhibitor. These results indicated that MPFC-mediated activation of the p38 MAPK
\end{abstract}

Correspondence to: Dr Haji Akber Aisa, The Key Laboratory of Plant Resources and Chemistry of Arid Zone, Xinjiang Technical Institute of Physics and Chemistry, Chinese Academy of Sciences, 40-1 Beijing Road, Urumqi, Xinjiang 830011, P.R. China E-mail: haji@ms.xjb.ac.cn

Key words: 4-methyl-6-phenyl-2H-furo[3,2-g]chromen-2-one, melanogenesis, protein kinase A pathway, p38 mitogen-activated protein kinase, the murine B16 melanoma cell and the protein kinase A (PKA) pathway may shed light on a novel approach for an effective therapy for vitiligo.

\section{Introduction}

Leukoderma, also named vitiligo, is an acquired disfiguring pigmentary anomaly of the skin manifested by depigmented white patches surrounded by a normal or hyper-pigmented border (1). Vitiligo affects $1-2 \%$ of the world population without racial or sex difference (2). Hypopigmentation may be the source of severe psychological distress, diminished quality of life, and increased risk of psychiatric morbidity (3). However, the effective medicines are largely absent from the clinical treatment of the disease.

Melanin synthesis in the skin plays an important evolutionary role in hypopigmentation therapy. In mammals, melanin biosynthesis is catalyzed by three melanocytespecific enzymes: tyrosinase (TYR), tyrosinase-related protein 1 (TRP1), and TRP2 (4). TYR is the rate-limiting enzyme in melanogenesis (5), catalyzing the hydroxylation of tyrosine to produce 3,4-dihydroxyphenylalanine (DOPA) and the oxidation of DOPA to DOPA quinone. TRP-1 and TRP-2 function in the biosynthesis of melanin downstream of TYR (4). Microphthalmia-associated transcription factor (MITF) has a crucial role in the transcription of melanogenic genes, binding a highly conserved motif termed M-box within the TYR promoter. Thereby MITF plays an important role in increasing melanogenesis $(6,7)$.

Many approaches have been used to help clarify the specific mechanism controlling melanin biosynthesis via tyrosinase regulation. The mitogen-activated protein kinases (MAPKs) are key signaling molecules related to the regulation of melanogenesis (8), including extracellular signal-regulating kinase (ERK), stress-activated protein kinase (SAPK)/JNK and p38 mitogen-activated protein kinase (p38 MAPK) signaling cascades. Previous literature showed that phosphorylation of p38 can lead to the activation of MITF via the phosphorylation of cyclic adenosinemonophosphate (cAMP) responsive element binding (CREB) protein. Some Chinese medicine extracts such as methyl 3,5-di-caffeoylquinate have been shown to have melanogenesis activity through activating the p38 signaling pathway (9). 
Another signaling pathway involved in melanogenesis regulation is protein kinase $\mathrm{A}$ (PKA). PKA can be activated by the elevation of cellular cAMP and cAMP stimulation results in the elevation of MITF protein levels and subsequent activation of the TYR, TRP-1 and TRP-2 promoters by binding with M-box or E-box consensus motif $(10,11)$.

Previous literature also showed that the inhibition of the PI3K/AKT pathway increases the production of melanin by MITF activation and induction of tyrosinase expression (12).

As an active compound, psoralen is present in a variety of traditional Chinese medicinal plants, such as Psoralea corylifolia L., Glehnia littoralis Fr. Schmidr ex Miq, Heracleum lanatum Michx., Ruta graveolens L. and Ficus carica L. Recent studies have revealed that it possesses significant pharmacological activities in dermatosis treatment, including vitiligo, psoriasis and alopecia areata. Similarly, the extract of Psoralea corylifolia L. seeds was one of the most popular Uygur medicines used for vitiligo and initially recorded in 'Yao Yong Zong Ku' around 300 years ago (13-15). In 1930s, 8-methoxypsoralen (8-MOP) and 5-methoxypsoralen (5-MOP) were isolated from the Psoralea corylifolia L. $(16,17)$. Later, other psoralens, such as 4,5,8-trimethylpsoralen (TMP) was synthesized as well. Continuous research proved that these compounds show strong activity in the treatment of vitiligo $(13,14)$. Among them, 8 -MOP is considered as a better therapeutic agent against vitiligo in consideration of low doses and toxicity. However, it is still accompanied by some undesired side effects in clinical therapy, such as gene mutation, skin phototoxicity and risk of skin cancer $(18,19)$. So, it is necessary to find substitutions for enhancing skin hyperpigmentation.

Our group has been dedicated to the drug development of vitiligo for many years (20-23). Recently, a new series of furocoumarin derivatives were designed and synthesized by our research team (20), and biologically evaluated for activity on tyrosinase and melanin synthesis in murine B16 cells. 4-Methyl6-phenyl-2H-furo[3,2-g]chromen-2-one (MPFC) (Fig. 1) is recognized as one of the most promising candidate compound with an effect on melanin synthesis and tyrosinase activity much better than the positive control 8-MOP. We speculate that better melanogenesis activity of MPFC may result from the different structural modifications compared with 8-MOP. In this study, we evaluated the activity of MPFC on melanogenesis and provide solid evidence showing that p38 MAPK and PKA pathway are targets of this compound to active melanin biosynthesis.

\section{Materials and methods}

Reagents. Dimethylsulfoxide (DMSO) was from Sigma (St. Louis, MO, USA), [2-(2-methoxy-4-nitrophenyl)-3-(4-nit rophenyl)-5-(2,4-disulfophenyl)-2H-tetrazolium] (CCK-8) was purchased from TransGen Biotechnology (Beijing, China). CERB, phospho-CREB (Ser133), AKT, p-AKT (Thr308), p38, p-p38 (Thr180/Tyr182), ERK, p-ERK (Thr202/Tyr204), JNK, p-JNK (Thr183/Tyr185) and $\beta$-actin antibodies were purchased from Cell Signaling Technology (Danvers, MA, USA). Antibodies against tyrosinase, TRP1 and TRP2 were from Santa Cruz Biotechnology, Inc. (Dallas, TX, USA). Anti-MITF antibody was purchased from Millipore (Billerica,
MA, USA). Anti-mouse, anti-goat and anti-rabbit IgG antibodies (horseradish peroxidase conjugated) were purchased from Santa Cruz Biotechnology, Inc.

Preperation of MPFC (20). Four percent ethanol potassium hydroxide solution $(70 \mathrm{ml})$ was added to an ethanolic solution $(500 \mathrm{ml})$ of intermediate 4-methyl-7-(2-oxo-2-phenylethoxy)$2 \mathrm{H}$-chromen-2-one (10 $\mathrm{mmol})$, and the mixture was refluxed for $4 \mathrm{~h}$. After cooling, the solution was acidified with $1 \mathrm{M}$ hydrochloric acid and extracted with ethyl acetate three times. The organic phase was dried overnight and evaporated under reduced pressure. The resulting residue was purified by silica gel chromatography with petroleum ether/ethyl acetate to obtain MPCF. Yield 97\%, light yellow solid, m.p. $171-173^{\circ} \mathrm{C}$; purity $98.70 \%$; ${ }^{1} \mathrm{H}$ NMR $(400 \mathrm{MHz}, \mathrm{CDCl} 3) \delta 7.98(\mathrm{~s}, 1 \mathrm{H}), 7.83$ (s, 1H), 7.64 (dd, J = 8.2, 1.1 Hz, 2H), 7.50-7.56 (m, 3H), 7.44 (td, J = 7.4, 1.1 Hz, 1H), 6.29 (s, 1H), 2.52 (s, 3H). ${ }^{13} \mathrm{C}$ NMR (101 MHz, $\left.\mathrm{CDCl}_{3}\right) \delta 160.99$ (s), 157.10 (s), 152.64 (s), 151.80 (s), 142.88 (s), 131.06 (s), 129.25 (s), 128.06 (s), 127.58 (s), 123.96 (s), 122.32 (s), 116.80 (s), 115.77 (s), 113.64 (s), 100.23 (s), 19.26 (s); IR (KBr) v: 2925, 1735, 1611, 1447, 1280, 1125, 1063, $831 \mathrm{~cm}^{-1}$; HRMS (ESI) calcd for $\mathrm{C}_{8} \mathrm{H}_{13} \mathrm{O}_{3}[\mathrm{M}+\mathrm{H}]^{+} 277.0865$, found 277.0853. MPFC was dissolved in DMSO and stored at $-20^{\circ} \mathrm{C}$ as a stock solution $(50 \mathrm{mM})$.

Cell culture. The murine B16 melanoma cell line (acquired from Chinese Academy of Sciences, Beijing, China) were grown in Dulbecco's modified Eagle's medium (DMEM) containing $10 \%$ heat-inactivated fetal bovine serum (FBS), penicillin $\mathrm{G}(100 \mathrm{U} / \mathrm{ml})$ and streptomycin $(100 \mathrm{mg} / \mathrm{ml})$ (Gibco-BRL, Grand Island, NY, USA) at $37^{\circ} \mathrm{C}$ in a humidified atmosphere of $5 \% \mathrm{CO}_{2}$.

Cell morphology and cell viability measurement. Cell morphology was examined under a LEICA DMI8 microscope (LEICA Microsystems CMS GmbH, Wetzlar, Germany). Cell viability was assayed by adding CCK-8 (TransGen Biotech) solution. Briefly, B16 cells were plated in 96-well dishes at a density of $5 \times 10^{3}$ cells/well and allowed to adhere for $24 \mathrm{~h}$. Test samples were added and the cells were incubated for $24 \mathrm{~h}$. After discarding the culture medium of the cells, $10 \mu \mathrm{l}$ of CCK- 8 solution was added into each well and cells were incubated at $37^{\circ} \mathrm{C}$ for another $2 \mathrm{~h}$. The absorbance was determined at $450 \mathrm{~nm}$ using a Spectra Max M5 (Molecular Devices, Sunnyvale, CA, USA). Absorbance of cells without treatment was regarded as $100 \%$ of cell survival. Each treatment was performed in triplicate and each experiment was repeated three times.

Tyrosinase activity assay. Tyrosinase activity was estimated by measuring the rate of L-DOPA oxidation. Briefly, B16 cells were seeded in a 6 -well plate at a density of $2 \times 10^{5}$ cells/well and allowed to attach for $24 \mathrm{~h}$. Test samples were then added to individual wells. After a $24 \mathrm{~h}$ incubation, cells were washed with ice-cold phosphate-buffered saline (PBS) twice, lysed with $1 \%$ Triton $\mathrm{X}-100$ solution containing $1 \%$ sodium deoxycholate for $30 \mathrm{~min}$ at $-80^{\circ} \mathrm{C}$, then the lysate was centrifuged at $12,000 \mathrm{x} \mathrm{g}$ for $15 \mathrm{~min}$ to obtain the supernatant. A reaction mixture containing $10 \mathrm{mM}$ L-DOPA in PBS ( $\mathrm{pH}$ 6.8) was added and then, the cells were incubated at $37^{\circ} \mathrm{C}$ in dark for 
$60 \mathrm{~min}$. The dopachrome was monitored by measuring the absorbance at $490 \mathrm{~nm}$ using an enzyme-linked immunosorbent assay (ELISA) reader and the treated cells were presented as percentage against the untreated cells. Each treatment was repeated three times.

Melanin measurement. B16 cells were seeded in a 6-well plate at a density of $2 \times 10^{5}$ cells/well and allowed to attach for $24 \mathrm{~h}$. Then adding test samples to individual wells, cells were incubated for $48 \mathrm{~h}$ and washed with PBS. After cells were lysed according to the method previously described (9), lysate was put in a 96-well microplate, and measured spectro-photometrically at $405 \mathrm{~nm}$ by a multi-plate reader. Protein concentration of each sample was determined by BCA Protein assay kit (Biomed, Beijing, China). The melanin amount expressed as $\mathrm{abs} / \mu \mathrm{g}$ protein was shown as percentage value. The percentage value of the treated cells were calculated with respect to the untreated cells. Each experiment was repeated three times.

Measurement of cAMP concentration. The cAMP level was measured using a cAMP ELISA kit (Cell Biolabs, Inc., San Diego, CA, USA) B16 cells were plated in a 6-well plate at a density of $5 \times 10^{5}$ cells/well and allowed to adhere for $24 \mathrm{~h}$, then test samples were added to individual wells. After incubating for $12 \mathrm{~h}, \mathrm{~B} 16$ cells were harvested and lysed in lysis buffer. Supernatants were collected after centrifuging to determine cAMP levels using a commercially available cAMP ELISA kit. cAMP levels were normalized to total protein content. Each experiment was repeated three times.

Western blot analysis. The treated cells were lysed in cold RIPA buffer ( $\mathrm{pH}$ 7.4) containing protease and protease inhibitor cocktail [1 M 4-nitrophenyl phosphate disodium salt hexahydrate (PNPP), $1 \mathrm{M}$ sodium fluoride $(\mathrm{NaF}), 10 \mathrm{mM}$ phenylmethanesulfonyl fluoride (PMSF), $100 \mathrm{mM}$ benzamidine, $100 \mathrm{mM}$ DL-Dithiothreitol (DTT), $200 \mathrm{mM}$ sodium orthovanadate (OV)]. The whole-cell lysate was collected and regarded as a protein sample. Its concentration was measured by BCA Protein assay kit (Biomed), $60 \mu \mathrm{g}$ of individual protein samples were separated by $10 \%$ sodium dodecyl sulfate (SDS) polyacrylamide gels at $100 \mathrm{~V}$ and transferred onto membranes for $2 \mathrm{~h}$ at $400 \mathrm{~mA}$. Following electrotransfer to polyvinylidene fluoride (PVDF) membranes (Merck Millipore Ltd., Darmstadt, Germany) membrane blocking was performed with $5 \%$ skim milk solution for $1 \mathrm{~h}$, then they were incubated with the primary antibodies at $4^{\circ} \mathrm{C}$ overnight. Equal loading was assessed using anti- $\beta$-actin antibody to normalize the amounts of total protein. After three washes with TBS containing $0.2 \%$ Tween-20 (TBST), the membranes were incubated with horseradish peroxidase-conjugated secondary antibodies at a dilution of 1:2,000 for $1 \mathrm{~h}$ at room temperature. The targeted proteins were detected by ECL western blot detection reagents (GE Healthcare, Pittsburgh, PA, USA), and visualized after exposure to chemiluminescence film (X-OMAT BT film; Carestream Health, Inc., Xiamen, China). Western blot assay results reported here are representative of at least three experiments.

Statistical analysis. Data were expressed as the mean \pm SD and statistical analysis was performed with one-way ANOVA

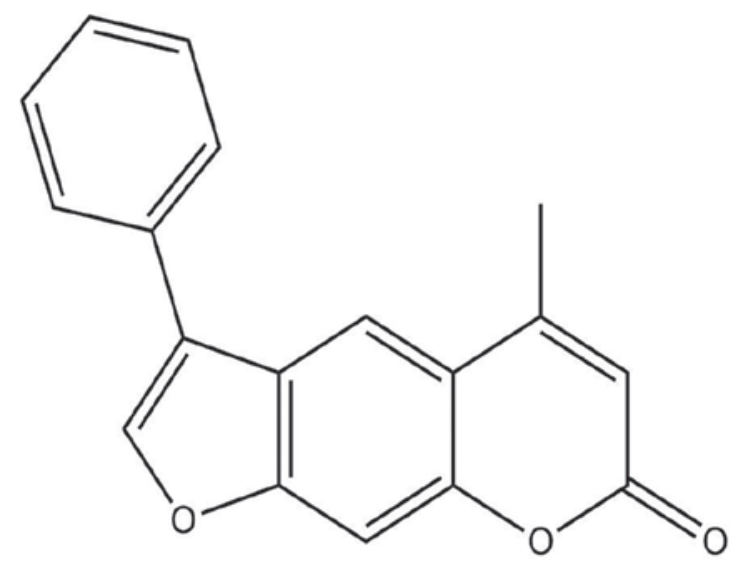

Figure 1. Chemical structure of 4-methyl-6-phenyl-2H-furo[3,2-g]chromen2-one (MPFC).

followed by Tukey post hoc test for multiple comparison tests. A P-value of $<0.05$ was considered of significant difference.

\section{Results}

Morphological changes of melanoma cells induced by $M P F C$. Our results showed that murine melanoma B16 cells treated with MPFC for $24 \mathrm{~h}$ did not induce any change in cell morphology when compared with the untreated cells (Fig. 2A) and did not show any increase in cytotoxicity (Fig. 2B). Thus, dosages at $0-50 \mu \mathrm{M}$ were chosen to determine the effects of MPFC on tyrosinase activity and melanin synthesis.

Treatment with MPFC stimulates tyrosinase activity and melanin content in B16 cells at non-cytotoxic dosages. Treatment with MPFC demonstrated the increased tyrosinase activity in a dose-dependent manner. At the same concentration of $50 \mu \mathrm{M}$, the tyrosinase activity of MPFC was increased by $20 \%$ compared with 8 -MOP $(0 \mu \mathrm{M}, 100 \pm 14.4 \% ; 12.5 \mu \mathrm{M}$, $108.1 \pm 3.9 \% ; 25 \mu \mathrm{M}, 125.9 \pm 10.6 \% ; 50 \mu \mathrm{M}, 149.8 \pm 3.9 \%$; 8-MOP, $50 \mu \mathrm{M}, 129.6 \pm 6.9 \%$ ) (Fig. 3A). As shown in Fig. 3B, melanin amount showed the same increasing trend in response to MPFC treatment, and the melanin content of MPFC was increased $90 \%$ more than 8 -MOP at $50 \mu \mathrm{M}(0 \mu \mathrm{M}$, $100 \pm 8.4 \% ; 12.5 \mu \mathrm{M}, 109.7 \pm 3.5 \% ; 25 \mu \mathrm{M}, 134.6 \pm 3.6 \% ; 50 \mu \mathrm{M}$, $213.3 \pm 16.4 \%$; 8 -MOP, $50 \mu \mathrm{M}, 124.2 \pm 2.4 \%$ ). These results provide a pharmacological basis for the traditional use of MPFC instead of 8-MOP in melanogenesis.

Effect of MPFC on the expression of TRPs. Since MPFC increased tyrosinase activity and melanin production, we explored the melanogenic signaling pathway related to the stimulatory activity of MPFC. After treatment with MPFC, the expression of melanogenesis-related proteins (MRPs) such as tyrosinase, TRP1, and TRP2 was examined by western blotting. MRP expression was clearly increased after treatment with MPFC in a dose-dependent manner (Fig. 4).

$M P F C$ induces $C R E B$ activation and enhances the expression of $p$-MITF. In order to elucidate how MPFC activates melanin synthesis, both CREB and MITF were hypothesized to be involved in MPFC-induced melanogenesis. As expected, 

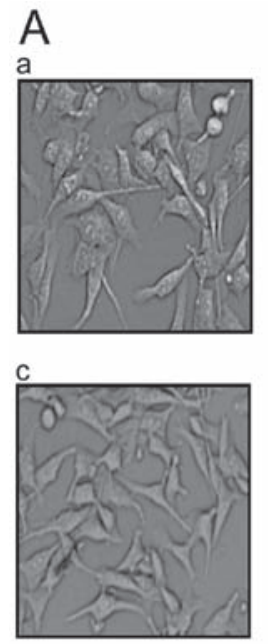
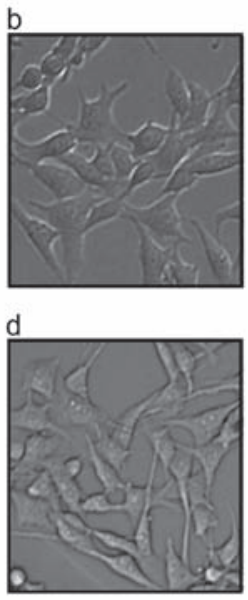

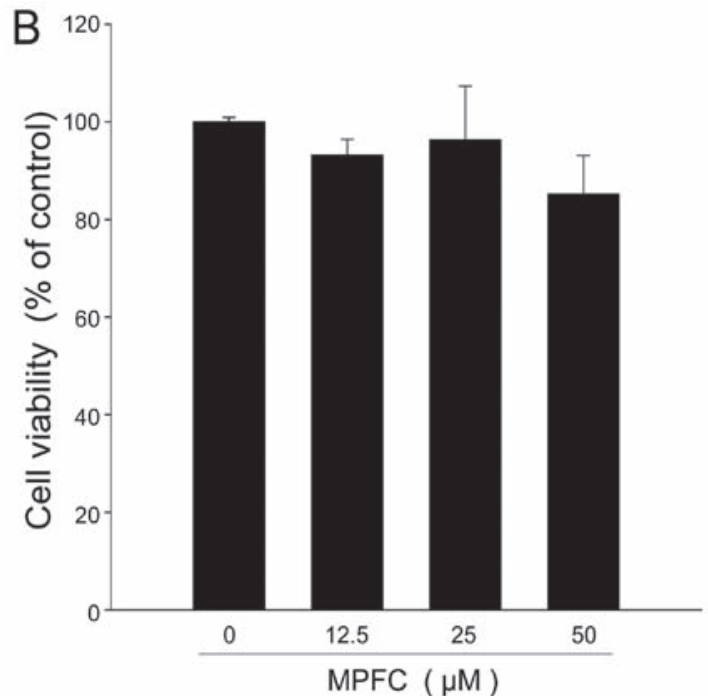

Figure 2. (A) (a-d) Effects of 4-methyl-6-phenyl-2H-furo[3,2-g]chromen-2-one (MPFC) on cell morphology. B16 cells were treated with $0.1 \%$ DMSO as vehicle or with MPFC at 12.5, 25 and $50 \mu \mathrm{M}$ for $24 \mathrm{~h}$. Cell morphology was observed under a microscope. Magnification, x200. (B) Effects of various concentrations of MPFC on cell viability. B16 melanoma cells were exposed to various concentrations of MPFC $(0,12.5,25$ and $50 \mu \mathrm{M})$ for $24 \mathrm{~h}$. Cell viability was measured by CCK- 8 assay. The data are shown as the means \pm SD; $n=3$.
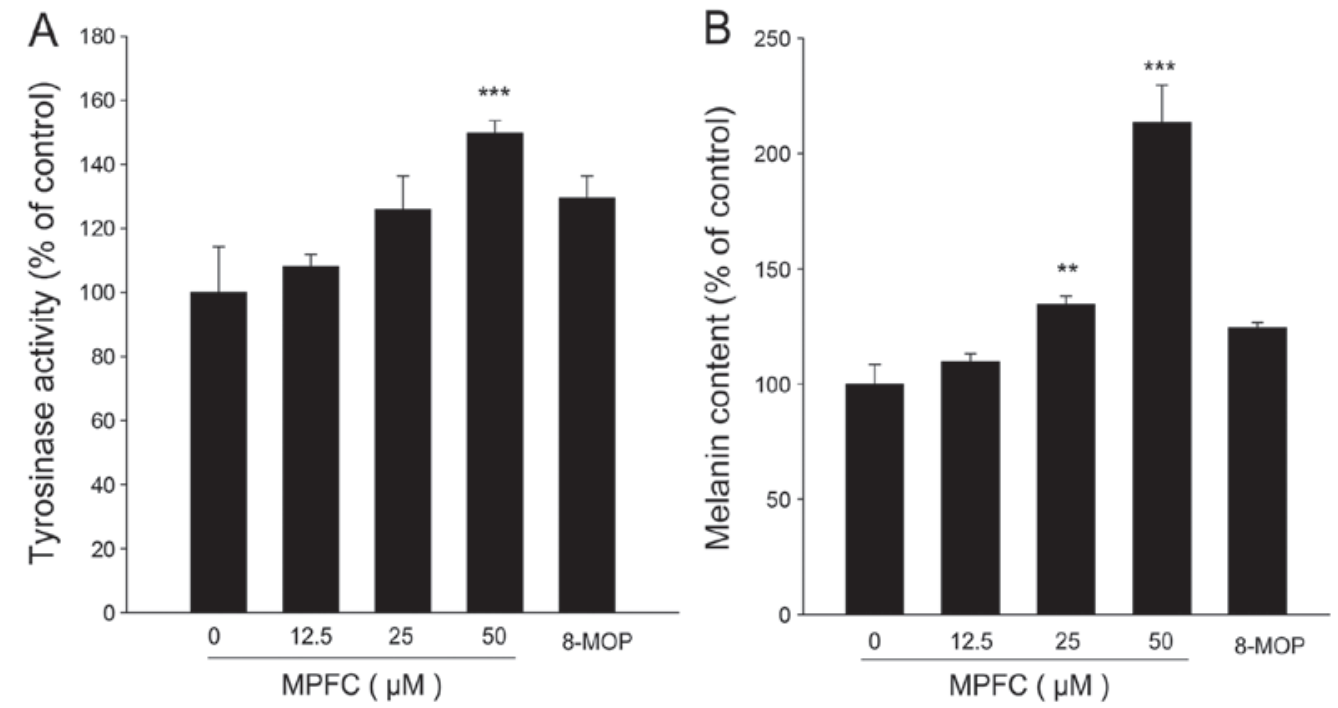

Figure 3. (A and B) Dose-dependent effect of 4-methyl-6-phenyl-2H-furo[3,2-g]chromen-2-one (MPFC) on tyrosinase activity and cellular melanin synthesis in B16 melanoma cells. Cells were treated with $0.1 \%$ DMSO as vehicle or with MPFC at 12.5, 25, 50 $\mu \mathrm{M}$ and 50 $\mu \mathrm{M}$ 8-methoxypsoralan (8-MOP) as positive control for 24 or $48 \mathrm{~h}$ to evaluate tyrosinase activity and melanin content, respectively. Each percentage value for treated cells is reported relative to that of $0.1 \%$ DMSO cells. Results are shown as the means $\pm \mathrm{SD} ; \mathrm{n}=3,{ }^{* *} \mathrm{P}<0.01$ and ${ }^{* * *} \mathrm{P}<0.001$ compared with $0.1 \%$ DMSO cells.

the expression of phosphorylated MITF by MPFC treatment for $48 \mathrm{~h}$ had a significant increase. Our results also showed that phosphorylation of CREB was clearly enhanced for $1 \mathrm{~h}$ (Fig. 5) compared with cells treated with $0.1 \%$ DMSO only, which suggested that MPFC-mediated elevation of the MITF may be cAMP-dependent.

MPFC induces melanin synthesis through intracellular cAMP accumulation and melanogenesis-related signaling pathways $P K A$. To evaluate the hypothesis above, we explored whether MPFC affects the accumulation of cAMP, which is a vital step in melanogenesis. As seen in Fig. 6A, $12 \mathrm{~h}$ after MPFC addition, the level of cAMP was increased. cAMP-related biological effects depend on PKA, which has a direct influ- ence on melanogenesis. Thus, we evaluated the effect of H-89 (Beyotime Biotechnology, Shanghai, China), an inhibitor of cAMP-dependent PKA, on the MPFC-mediated induction of tyrosinase activity and melanin content. As shown in Fig. 6B, MPFC-induced enhancement of tyrosinase activity on incubation for $24 \mathrm{~h}$ was abrogated by H-89. In addition, the melanin content after MPFC treatment for $48 \mathrm{~h}$ also reduced by H-89 compared with untreated cells (Fig. 6C). Generally, these results revealed the critical involvement of cAMP/PKA signaling in MPFC-mediated melanogenesis in B16 melanoma cells.

MPFC induces activation of $p 38$ MAPK. The phosphorylation of MAPK or inhibition of PI3K/AKT activation was reported 
0

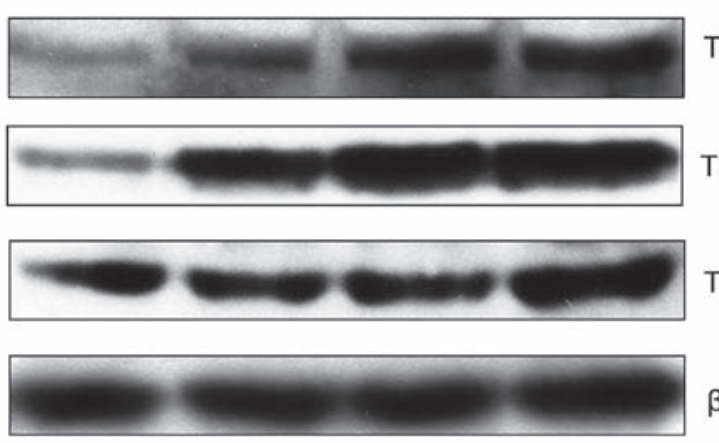

$\beta$-actin

TRP1

TRP2
Tyrosinase

Figure 4. Representative western blot analyses illustrating expression of tyrosinase-related proteins (TRPs). B16 cells were treated with 4-methyl6-phenyl- $2 \mathrm{H}$-furo[3,2-g]chromen-2-one (MPFC) at $0,12.5,25$ and $50 \mu \mathrm{M}$ for $48 \mathrm{~h}$. Tyrosinase, TRP1 and TRP2 protein expression were detected by western blotting. Results were normalized against $\beta$-actin expression.

to be the signaling process in hyperpigmentation. Thus, we performed western blot analysis the impact of MPFC on p38, ERK, JNK and AKT phosphorylation. As shown in Fig. 7, phosphorylation of p38 MAPK was significantly increased after $1 \mathrm{~h}$ at different concentrations of MPFC treatment compared with untreated cells. In contrast, no significant upregulation of AKT phosphorylation was induced by MPFC.

Effects of inhibitors of MAPKs and AKT on MPFCinduced tyrosinase activity and melanin content. Even co-treatment with ERK inhibitor (PD98059), JNK inhibitor (SP600125) (Beyotime Biotechnology) or AKT inhibitor IV (EMD Biosciences, Inc., Madison, WI, USA), MPFC-induced tyrosinase activity and melanin content were not influenced. However, the p38 MAPK inhibitor SB203580 (Beyotime Biotechnology) significantly reduced MPFC-triggered tyrosinase activity and melanin content (Fig. 8). These observations reveal that $\mathrm{p} 38$, but not ERK, JNK or AKT pathway, was directly involved in the upstream pathway of melanogenesis mediated by MPFC.

\section{Discussion}

In hypopigmentation therapy $(24,25)$, the induction of melanin production was the focus of study to develop effective treatments $(2,3,26,27)$. Natural resources have been screened and active compounds have been synthesized for the development of pigmentation agents by our research group, including chlorogenic acid (22), kaliziri extracts (23), furocoumarin derivatives (20) and isoxazole chalcone derivatives (21).

Recently, Niu et al (20) synthesized a series of furocoumarin derivatives and discovered that many of them have strong activities in melanogenesis. In consideration of the generally low cytotoxicities of these compounds, we tested all of the derivatives in B16 melanoma cells, and identified that MPFC, a psoralen derivative, was an effective tyrosinase activitor in our recent report. The melanin content and tyrosinase activity increased by 90 and 20\%, respectively, in B16 cells treated with MPFC compared with 8-MOP treated controls in our research. We infer that the in vitro melanin synthesis evaluation of these structurally diverse analogues attributed to an

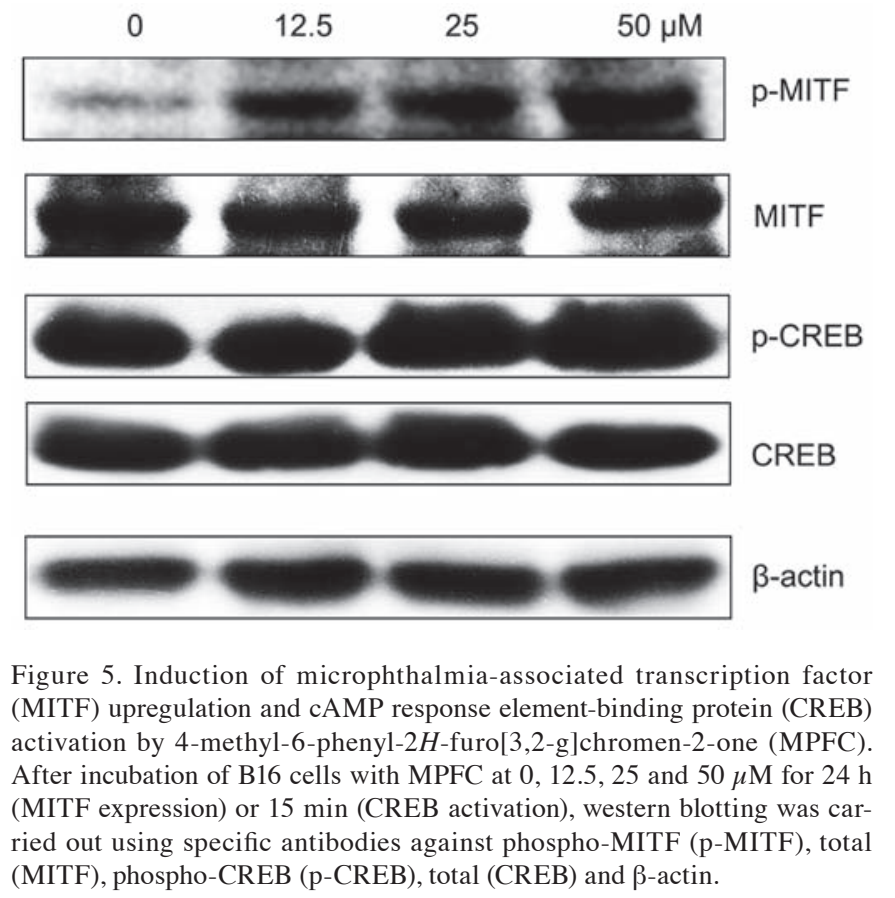

outline of structure-activity relationship. Studies $(31,32)$ have reported that 8 -MOP leads to dramatic increases in melanin production through activating the protein kinase $\mathrm{A}$ and/or protein kinase $\mathrm{C}$ signaling pathways. By comparison, the regulation of MPFC in melanin synthesis results from cross-talk between several different signaling pathways.

As mentioned in the introduction, phosphorylation of MAPK (including ERK, JNK and p38 MAPKs) or inhibition of PI3K/AKT activation has been reported as one of the signaling processes in hyperpigmentation (33). It has been shown that p38 MAPK activates MITF through the phosphorylation of CREB, which in turn upregulates the expression of tyrosinase, TRP-1 and TRP-2, resulting in melanin production $(34,35)$. Activations of the ERK signaling (36) and the JNK/SAPK pathways (37) are related to the downregulation of melanogenesis. Another signaling pathway involved in melanogenesis regulation includes phosphatidylinositol 3-kinase (PI3K)/AKT signaling, which phosphorylates MITF and promotes its activation, leading to melanogenesis enhancement $(38,39)$. In our experiments, treatment with MPFC did not affect the total protein levels of ERK, JNK, AKT or p38. However, it significantly promoted the levels of p-p38, although not p-ERK, p-JNK and p-AKT in B16 cells. To verify whether p38 MAPK signaling factors are responsible for MPFC-induced activation effects on melanogenesis, co-incubation with p38 MAPK inhibitor SB203580 clearly abrogated MPFC-stimulated melanin content and tyrosinase activity. Unlike its effect on p38 MAPK, other inhibitors did not influence the MPFC-stimulated melanogenic process. These results suggested that p38 MAPK is responsible for the pigmentation process mediated by MPFC in melanoma cells among the upstream pathways involved in melanogenesis. The activation effects on melanogenesis of MPFC and phosphorylation of p38 demonstrated in our research are consistent with the above mentioned role of p38 signaling pathway in hyperpigmentation. 

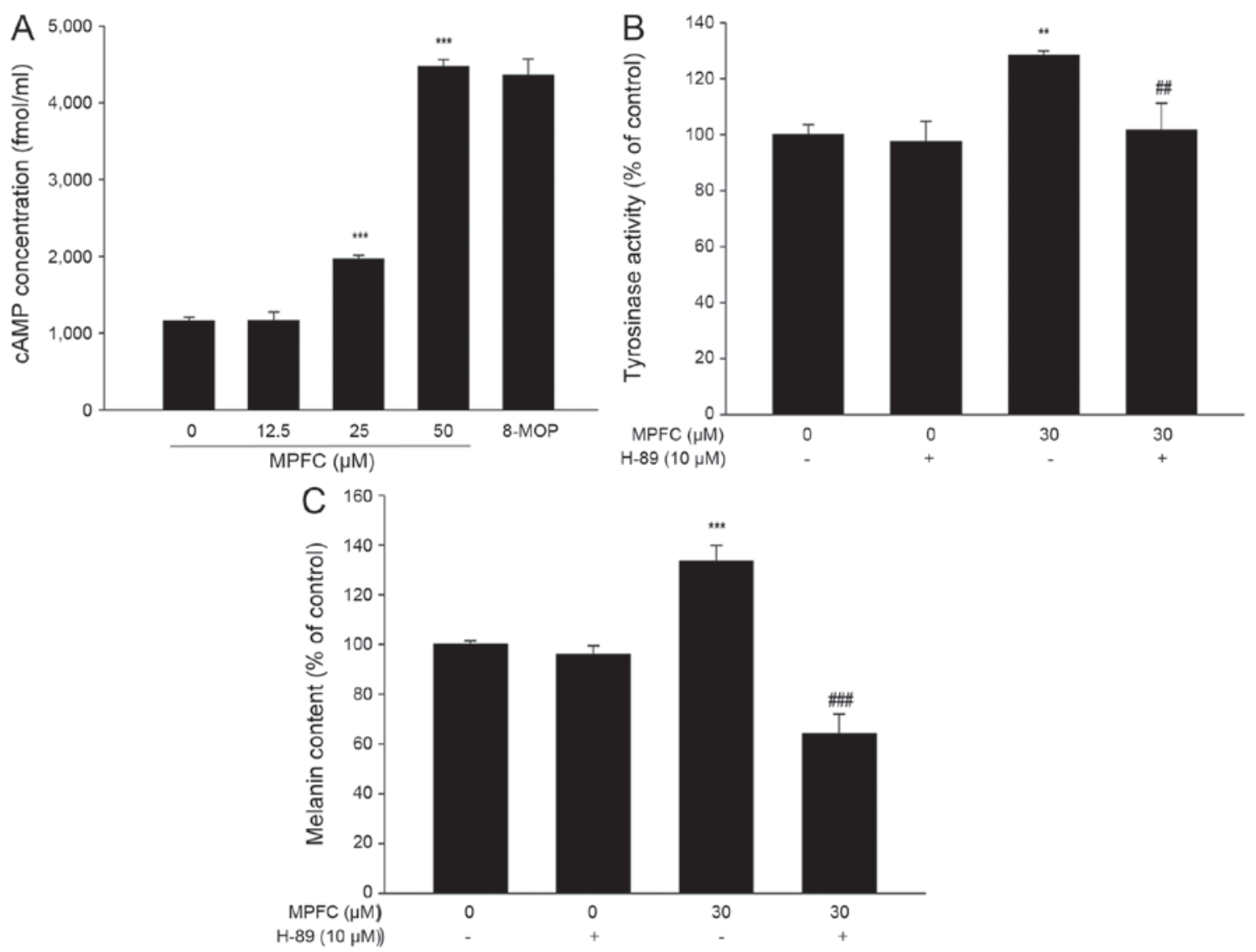

Figure 6. (A) Enhancing effect of 4-methyl-6-phenyl-2H-furo[3,2-g]chromen-2-one (MPFC) on intracellular cyclic adenosinemonophosphate (cAMP) accumulation. Cells were treated with $0,12.5,25,50 \mu \mathrm{M}$ MPFC and $50 \mu \mathrm{M}$ 8-methoxypsoralan (8-MOP) as positive control for the indicated times. Intracellular cAMP levels were measured using an enzyme immunoassay protocol. (B and C) Induction of cAMP level by MPFC. B16 cells were pre-incubated with H-89 $(10 \mu \mathrm{M})$ for $2 \mathrm{~h}$ before MPFC $(30 \mu \mathrm{M})$ was added, and then incubated for 24 or $48 \mathrm{~h}$ for the tyrosinase activity and melanin content, respectively. Values are expressed as the mean $\pm \mathrm{SD}$ of three separate experiments. ${ }^{* *} \mathrm{P}<0.01$ and ${ }^{* * *} \mathrm{P}<0.001$ compared with untreated cells; ${ }^{\# \# / 4} \mathrm{P}<0.01$ and ${ }^{\# \# \#} \mathrm{P}<0.001$ compared with MPFC stimulation.

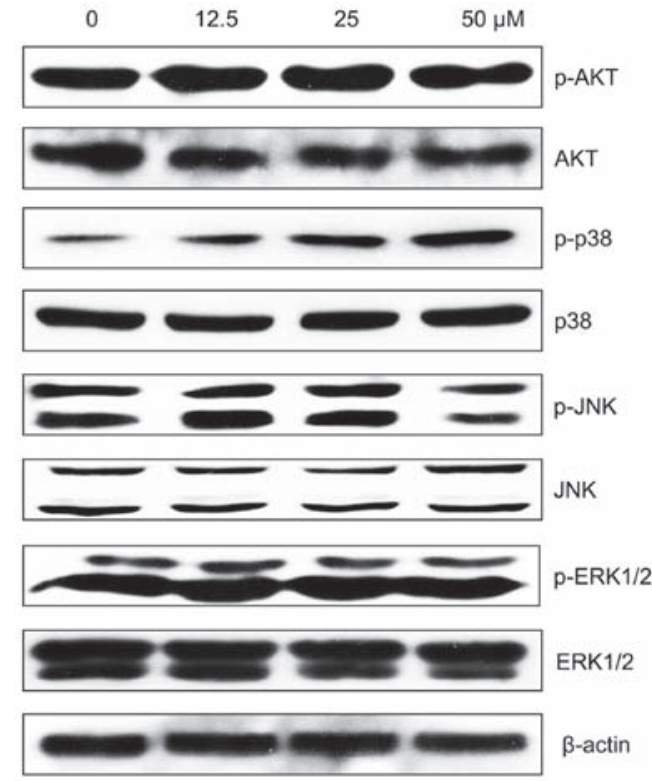

Figure 7. Western blot assays were used to examine the expression of MAPKs and AKT signaling pathway. B16 cells were treated with 4-methyl-6-phenyl$2 \mathrm{H}$-furo[3,2-g]chromen-2-one (MPFC) at the $0,12.5,25$ and $50 \mu \mathrm{M}$ for $15 \mathrm{~min}$, the phosphorylation and total of AKT, p38, JNK and extracellular signal-regulating kinase 1/2 (ERK1/2) were measured by western blotting. Equal protein loading amounts were confirmed by $\beta$-actin expression.
The PKA-dependent signaling pathway has also been reported as one of the signaling processes in hyperpigmentation (40). There is evidence that intracellular cAMP promotes MITF expression via phosphorylating the CREB family transcription factors. Once phosphorylated, CREB can upregulate MITF and subsequently results in the indirect activation of the tyrosinase promoter by MITF (41). In accordance with previous studies, we observed that MPFC induces the phosphorylation of CREB and enhances the production of cAMP compared with untreated cells. It is noteworthy that 8-MOP showed the same increasing trend in response to MPFC treatment in cAMP level, the results agreed with the experimental results from literature $(31,32)$. $\mathrm{H}-89$, an inhibitor of protein kinase A, completely abolished tyrosinase expression in $\mathrm{B} 16$ cells induced by MPFC, indicating that MPFC-mediated MITF activation relies on PKA signaling pathway.

In conclusion, MPFC enhanced melanin synthesis and tyrosinase activity through accelerating p38 MAPK and PKA signaling pathways. These results provide a molecular function for psoralen derivative components in melanogenesis and will help expand our knowledge of clinical therapy for enhancing skin hyperpigmentation. 

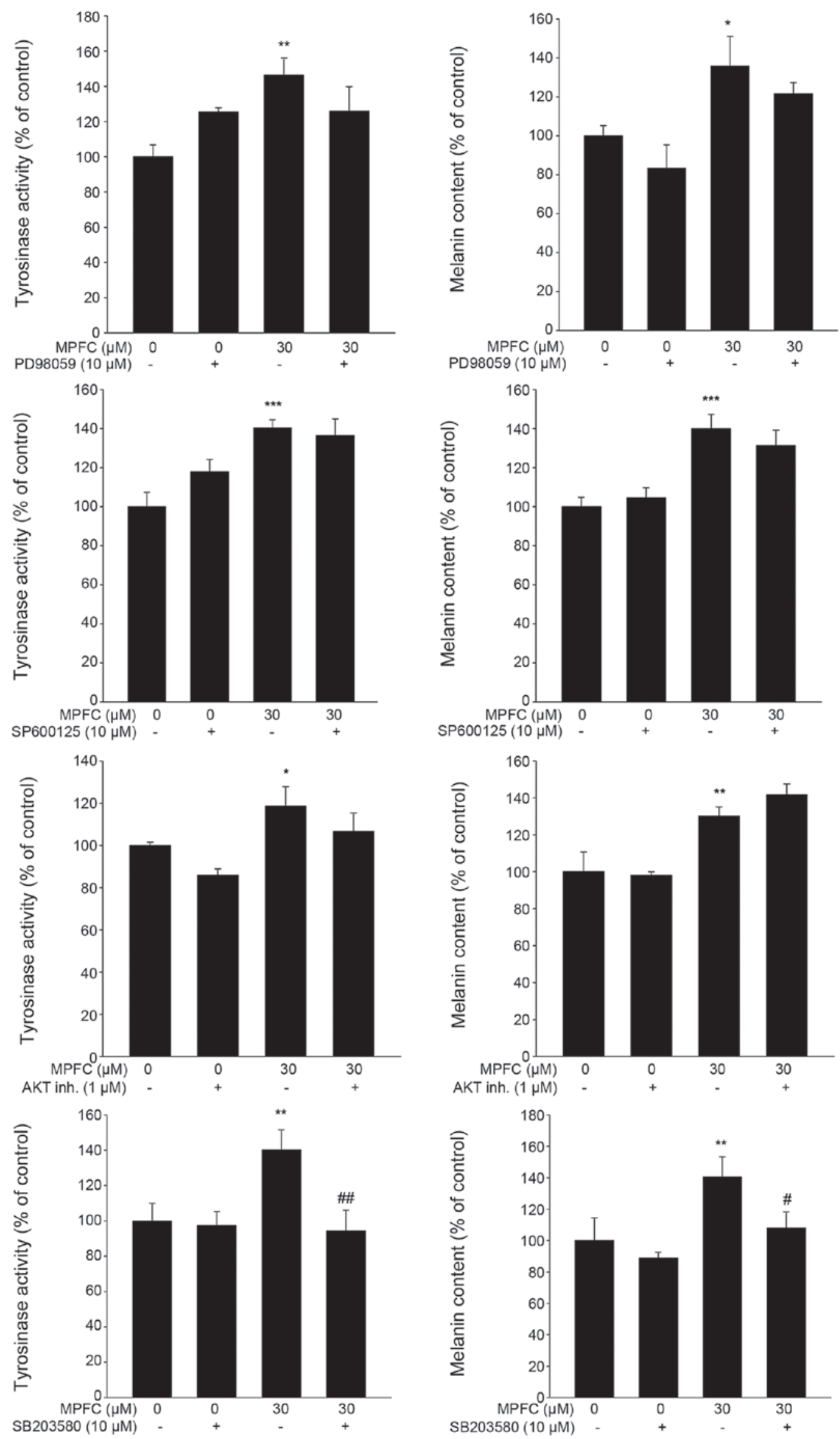

Figure 8. Effects of inhibitors of MAPKs and AKT on 4-methyl-6-phenyl-2H-furo[3,2-g]chromen-2-one (MPFC)-induced tyrosinase activity and melanin content. Inhibitors (PD98059, SP600125 and SB203580 $10 \mu \mathrm{M}$, AKT inhibitor IV1 $\mu \mathrm{M}$ ) were pre-incubated with B16 cells for $2 \mathrm{~h}$ before addition of MPFC at $30 \mu \mathrm{M}$, followed by an additional incubation for 24 or $48 \mathrm{~h}$ for tyrosinase activity and melanin content, respectively. Each percentage value in the treated cells was calculated with respect to that in the untreated cells. Values are expressed as the mean $\pm \mathrm{SD}$ of three separate experiments. ${ }^{*} \mathrm{P}<0.05,{ }^{* * *} \mathrm{P}<0.01$ and ${ }^{* * *} \mathrm{P}<0.001$ compared with control; ${ }^{*} \mathrm{P}<0.05$ and ${ }^{\# \#} \mathrm{P}<0.01$ compared with MPFC stimulation. 


\section{Acknowledgements}

Not applicable.

\section{Funding}

This study was funded by the Projects of International Science \& Technology Cooperation of the Xinjiang Uyghur Autonomous Region (no. 20146020), the Key Research and Development Project Ofxinjiang Autonomous Region (no. 2016B03038-3) and Personalized Medicines-Molecular Signature-based Drug Discovery and Development, Strategic Priority Research Program of the Chinese Academy of Sciences (no. xDA12050301).

\section{Availability of data and material}

The datasets used and analyzed during the current study are available from the corresponding author on reasonable request.

\section{Authors' contributions}

LY, GP and CN conceived and designed the experiments and wrote the paper. LY and CN performed the experiments.GP, HAA and JD analyzed the data. HAA revised the paper. All authors read and approved the final manuscript.

\section{Ethics approval and consent to participate}

Not applicable.

\section{Consent for publication}

Not applicable.

\section{Competing interests}

The authors declare that they have no competing interests.

\section{References}

1. Donata, Kesavan M, Austin, Mohan KS, Rajagopalan K and Kuttan R: Clinical trial of certain ayurvedic medicines indicated in vitiligo. Anc Sci Life 9: 202-206, 1990.

2. Lotti T, Zanardelli M and D'Erme AM: Vitiligo: What's new in the psycho-neuro-endocrine-immune connection and related treatments. Wien Med Wochenschr 164: 278-285, 2014.

3. Alikhan A, Felsten LM, Daly M and Petronic-Rosic V: Vitiligo: A comprehensive overview Part I. Introduction, epidemiology, quality of life, diagnosis, differential diagnosis, associations, histopathology, etiology, and work-up. J Am Acad Dermatol 65: 473-491, 2011.

4. Narumol Silpa-Archa, Sunatra Nitayavardhana, Kanchalit Thanomkitti, Leena Chularojanamontri, Supenya Varothai and Chanisada Wongpraparut: Comparison of the efficacy and safety of $0.1 \%$ tacrolimus ointment and $0.1 \%$ mometasonefuroate cream for adult vitiligo: A single-blinded pilot study. Dermatologica Sinica 34: 177-179, 2016.

5. Park SH, Kim DS, Kim WG, Ryoo IJ, Lee DH, Huh CH, Youn SW, Yoo ID and Park KC: Terrein: A new melanogenesis inhibitor and its mechanism. Cell Mol Life Sci 61: 2878-2885, 2004.

6. Hearing VJ: Biochemical control of melanogenesis and melanosomal organization. J Investig Dermatol Symp Proc 4: 24-28, 1999.
7. Screaton RA, Conkright MD, Katoh Y, Best JL, Canettieri G, Jeffries S, Guzman E, Niessen S, Yates JR III, Takemori H, et al: The CREB coactivator TORC2 functions as a calcium- and cAMP-sensitive coincidence detector. Cell 119: 61-74, 2004.

8. Zhou J, Shang J, Ping F and Zhao G: Alcohol extract from Vernonia anthelmintica (L.) willd seed enhances melanin synthesis through activation of the p38 MAPK signaling pathway in B16F10 cells and primary melanocytes. J Ethnopharmacol 143: 639-647, 2012.

9. Kim HJ, Kim JS, Woo JT, Lee IS and Cha BY: Hyperpigmentation mechanism of methyl 3,5-di-caffeoylquinate through activation of $\mathrm{p} 38$ and MITF induction of tyrosinase. Acta Biochim Biophys Sin (Shanghai) 47: 548-556, 2015.

10. Hemesath TJ, Price ER, Takemoto C, Badalian T and Fisher DE: MAP kinase links the transcription factor microphthalmia to c-Kit signalling in melanocytes. Nature 391: 298-301, 1998.

11. Price ER, Ding HF, Badalian T, Bhattacharya S, Takemoto C, Yao TP, Hemesath TJ and Fisher DE: Lineage-specific signaling in melanocytes. C-kit stimulation recruits p300/CBP to microphthalmia. J Biol Chem 273: 17983-17986, 1998.

12. Shen T, Heo SI and Wang MH: Involvement of the p38 MAPK and ERK signaling pathway in the anti-melanogenic effect of methyl 3,5-dicaffeoyl quinate in B16F10 mouse melanoma cells. Chem Biol Interact 199: 106-111, 2012.

13. El Mofty and AM: Vitiligo and Psoralens. Pergamon Press, Oxford, pp1147-1195, 1968.

14. Fitzpatrick TB, Parrish JA and Pathak MA: Phototherapy of vitiligo (idiopatic leukodermia). In: Sunlight and Man: Normal and abnormal photobiologic responses. Tokyo University Press, Tokyo, pp783-791, 1974.

15. Parrish JA, Fitzpatrick TB, Shea C and Pathak MA: Photochemotherapy of vitiligo. Use of orally administered psoralens and a high-intensity long-wave ultraviolet light system. Arch Dermatol 112: 1531-1534, 1976.

16. Jois HS, Manjunath BL and Venkatarao SJ: Chemical examination of the seeds of Psoralea corylifolia. J Indian Chem Soc 10: 41, 1933.

17. Späth E and Kainrath P: Über Bergamottin und über die Auffindung von Limettin im Bergamottöl (XXXIV. Mitteil. über natürliche Cumarine). Ber Dtsch Chem Ges 70: 2272-2276, 1937 (In German).

18. Felsten LM, Alikhan A and Petronic-Rosic V: Vitiligo: a comprehensive overview Part II: treatment options and approach to treatment. J Am Acad Dermatol 65: 493-514, 2011.

19. Tippisetty S, Goudi D, Mohammed AW and Jahan P: Repair efficiency and PUVA therapeutic response variation in patients with vitiligo. Toxicol In Vitro 27: 438-440, 2013.

20. Niu C, Pang GX, Li G, Dou J, Nie LF, Himit H, Kabas M and Aisa HA: Synthesis and biological evaluation of furocoumarin derivatives on melanin synthesis in murine B16 cells for the treatment of vitiligo. Bioorg Med Chem 24: 5960-5968, 2016.

21. Niu C, Yin L, Nie LF, Dou J, Zhao JY, Li G and Aisa HA: Synthesis and bioactivity of novel isoxazole chalcone derivatives on tyrosinase and melanin synthesis in murine B16 cells for the treatment of vitiligo. Bioorg Med Chem 24: 5440-5448, 2016.

22. Li HR, Habasi M, Xie LZ and Aisa HA: Effect of chlorogenic acid on melanogenesis of B16 melanoma cells. Molecules 19: 12940-12948, 2014.

23. Tuerxuntayi A, Liu YQ, Tulake A, Kabas M, Eblimit A and Aisa HA: Kaliziri extract upregulates tyrosinase, TRP-1, TRP-2 and MITF expression in murine B16 melanoma cells. BMC Complement Altern Med 14: 166-174, 2014.

24. Westerhof $\mathrm{W}$ and d'Ischia M: Vitiligo puzzle: The pieces fall in place. Pigment Cell Res 20: 345-359, 2007.

25. Spritz RA: The genetics of generalized vitiligo and associated autoimmune diseases. Pigment Cell Res 20: 271-278, 2007.

26. Guerra L, Dellambra E, Brescia S and Raskovic D: Vitiligo: Pathogenetic hypotheses and targets for current therapies. Curr Drug Metab 11: 451-467, 2010.

27. Taieb A, Alomar A, Böhm M, Dell'anna ML, De Pase A, Eleftheriadou V, Ezzedine K, Gauthier Y, Gawkrodger DJ, Jouary T, et al; Vitiligo European Task Force (VETF); European Academy of Dermatology and Venereology (EADV); Union Europeenne des Medecins Specialistes (UEMS): Guidelines for the management of vitiligo: the European Dermatology Forum consensus. Br J Dermatol 168: 5-19, 2013.

28. Eun JS, Kim KS, Kim HN, Park SA, Ma TZ, Lee KA, Kim DK, Kim HK, Kim IS, Jung YH, et al: Synthesis of psoralen derivatives and their blocking effect of hKv1.5 channel. Arch Pharm Res 30: 155-160, 2007. 
29. Grass JA, Hei DJ, Metchette K, Cimino GD, Wiesehahn GP, Corash L and Lin L: Inactivation of leukocytes in platelet concentrates by photochemical treatment with psoralen plus UVA. Blood 91: 2180-2188, 1998.

30. Chakraborty DP, Roy S and Chakraborty AK: Vitiligo, psoralen, and melanogenesis: Some observations and understanding. Pigment Cell Res 9: 107-116, 1996.

31. Kanof NB: Melanin formation in vitiliginous skin under the influence of external applications of 8-methoxypsoralen. J Invest Dermatol 24: 5-10, 1955.

32. Lei TC, Virador V, Yasumoto K, Vieira WD, Toyofuku K and Hearing VJ: Stimulation of melanoblast pigmentation by 8-methoxypsoralen: The involvement of microphthalmia-associated transcription factor, the protein kinase a signal pathway, and proteasome-mediated degradation. J Invest Dermatol 119: 1341-1349, 2002.

33. Park HY and Gilchrest BA: Signaling pathways mediating melanogenesis. Cell Mol Biol (Noisy-le-grand) 45: 919-930, 1999.

34. Bellei B, Maresca V, Flori E, Pitisci A, Larue L and Picardo M p38 regulates pigmentation via proteasomal degradation of tyrosinase. J Biol Chem 285: 7288-7299, 2010.

35. Ye Y, Chu JH, Wang H,xu H, Chou GX, Leung AK, Fong WF and Yu ZL: Involvement of p38 MAPK signaling pathway in the anti-melanogenic effect of San-bai-tang, a Chinese herbal formula, in B16 cells. J Ethnopharmacol 132: 533-535, 2010.
36. Kim DS, Jeong YM, Park IK, Hahn HG, Lee HK, Kwon SB, Jeong JH, Yang SJ, Sohn UD and Park KC: A new 2-imino1,3-thiazoline derivative, KHG22394, inhibits melanin synthesis in mouse B16 melanoma cells. Biol Pharm Bull 30: 180-183, 2007.

37. Bu J, Ma PC, Chen ZQ,Zhou WQ,Fu YJ,Li LJ and Li CR: Inhibition of MITF and tyrosinase by paeonol-stimulated JNK/SAPK to reduction of phosphorylated CREB. Am J Chin Med 36: 245-263, 2008.

38. Oka M, Nagai H, Ando H, Fukunaga M, Matsumura M, Araki K, Ogawa W, Miki T, Sakaue M, Tsukamoto K, et al: Regulation of melanogenesis through phosphatidylinositol 3-kinase-Akt pathway in human G361 melanoma cells. J Invest Dermatol 115: 699-703, 2000.

39. Khaled M, Larribere L, Bille K, Aberdam E, Ortonne JP, Ballotti R and Bertolotto C: Glycogen synthase kinase 3beta is activated by cAMP and plays an active role in the regulation of melanogenesis. J Biol Chem 277: 33690-33697, 2002.

40. Hirata N, Naruto S, Ohguchi K, Akao Y, Nozawa Y, Iinuma M and Matsuda $\mathrm{H}$ : Mechanism of the melanogenesis stimulation activity of (-)-cubebin in murine B16 melanoma cells. Bioorg Med Chem 15: 4897-4902, 2007.

41. Ganss R, Schütz G and Beermann F: The mouse tyrosinase gene. Promoter modulation by positive and negative regulatory elements. J Biol Chem 269: 29808-29816, 1994. 